\title{
Need to Inspect the Total Gastrointestinal Tract of Patients With Malignant Lymphomas
}

\author{
YUKI MARUYAMA ${ }^{1}$, TAKUJI YAMASAKI ${ }^{1}$, HARUNA MIYASHITA $^{1}$, YOSHIHIRO AKITA $^{1}$, \\ YUSUKE NAGATA ${ }^{1}$, RYOSUKE MIYAZAKI ${ }^{1}$, MASAAKI NOGUCHI ${ }^{1}$, RYOICHI SAWADA ${ }^{1}$, AKIHISA HIDAKA ${ }^{1}$, \\ TOSHIYUKI SAKURAI ${ }^{1}$, TOMOHIRO KATO ${ }^{1}$, KAZUKI SUMIYAMA $^{2}$ and MASAYUKI SARUTA ${ }^{1}$ \\ ${ }^{1}$ Division of Gastroenterology and Hepatology, Department of Internal Medicine, \\ The Jikei University School of Medicine, Tokyo, Japan; \\ ${ }^{2}$ Department of Endoscopy, The Jikei University School of Medicine, Tokyo, Japan
}

\begin{abstract}
Background/Aim: Malignant lymphoma (ML) cases with overlapping gastrointestinal (GI) lesions are often encountered. We aimed to elucidate the importance of examining the GI tract in patients with $M L$ and assess the overlap rate. Patients and Methods: We analysed 190 patients diagnosed with GI MLs. We compared the overlap rates among the different histopathological types. Results: Twenty-five (13.2\%) patients had overlapping GI lesions in more than two segments. The overlap rates were $100 \%$ in mantle cell lymphomas (MCL), $27.6 \%$ in follicular lymphomas $(F L)$, and $16.3 \%$ in diffuse large B-cell lymphomas (DLBCL). MCL, FL, and DLBCL cases showed significantly higher overlap rates than mucosa-associated lymphoid tissue lymphoma cases $(p<0.01)$. About $64.0 \%$ of cases of ML with overlapping lesions involved the small intestine. Conclusion: In GI ML cases, it is ideal to examine the entire GI tract by esophagogastroduodenoscopy, colonoscopy, and capsule endoscopy and/or balloon-assisted endoscopy, especially in $M C L, F L$, and $D L B C L$.
\end{abstract}

Malignant lymphomas (MLs) are classified as either Hodgkin's or non-Hodgkin's lymphomas. Non-Hodgkin MLs are sub-divided into nodal and extranodal lymphomas. Although primary gastrointestinal (GI) MLs comprise only

This article is freely accessible online.

Correspondence to: Takuji Yamasaki, Division of Gastroenterology and Hepatology, Department of Internal Medicine, The Jikei University School of Medicine, 3-25-8, Nishi-shimbashi, MinatoKu, Tokyo, 105-8461, Japan. Tel: +81 334331111, Fax: +81 334331111, e-mail: takusan.yamasan@gmail.com

Key Words: Non-Hodgkin lymphoma, extranodal malignant lymphoma, B-cell lymphoma, gastrointestinal malignant lymphoma, capsule endoscopy, balloon-assisted endoscopy, mantle cell lymphoma, follicular lymphoma.
$1-8 \%$ of all GI malignancies (1-4), they account for $30-40 \%$ of all extranodal MLs and are the most common type of extranodal MLs (4, 5). Esophagogastroduodenoscopy (EGD) and total colonoscopy (TCS) were previously used to identify ML lesions mainly in the stomach and large intestine. Recently, EGD and TCS have been standardized globally as feasible approaches for identifying ML lesions because they can easily detect GI ML. Furthermore, balloonassisted endoscopy (BAE) and capsule endoscopy (CE) reportedly improve the rate of diagnosis of small intestinal MLs. Treatment modalities for GI MLs include the "watch and wait" strategy, antibiotics (e.g., those targeting Helicobacter pylori), radiotherapy, chemotherapy, surgical resection, immunotherapy (e.g., rituximab), and combinations of these options (6). Given that optimal therapeutic strategies should be determined based on the location of the lesion, histological type, and clinical stage, we think it is also important to examine the small intestine, which has not been investigated for a long time, especially in cases of GI ML. Several studies have reported overlaps in GI MLs $(1,3,4,7-9)$. To the best of our knowledge, only few studies have investigated the presence or absence of overlaps in small bowel lesions. Therefore, herein, we aimed to elucidate the importance and the need for examining the GI tract as comprehensively as possible in patients with ML and to assess the overlap rate of GI MLs.

\section{Patients and Methods}

Patients and design. All consecutive adult Japanese patients histologically diagnosed with GI ML at our institution between October 2007 and January 2021 were recruited from an institutional review board-approved GI ML database, and their medical charts were reviewed retrospectively. All patients met the diagnostic criteria for GI lymphoma, as previously defined (7). Clinical features (histopathological type, localizations, overlap rate, and clinical stage) were analysed retrospectively. The diagnosis of GI ML was based on endoscopic findings and histopathological 
diagnosis. All histological materials were obtained by endoscopic biopsy or surgery, and tissue specimens were stained with haematoxylin and eosin. In all specimens, immunostaining for CD3 and $\mathrm{CD} 20$ was performed to distinguish between T- and B-cell lymphomas. Additional staining was performed, on demand, using antibodies specific for CD5, CD10, CD23, CD43, CD45RO, CD79a, B-cell lymphoma (BCL)-2, BCL-6, cyclin D1, MIB-1, cmyc, Epstein-Barr virus small RNA, terminal deoxynucleotidyl transferase, and immunoglobulin light chains ( $\mathrm{K}$ and $\lambda$ ). Tissues were classified according to the guidelines of the World Health Organization for hematopoietic/lymphoid tumours (5). Based on immunohistochemical staining results, 186 cases were diagnosed as BCLs, and 4 cases were diagnosed as T-cell lymphomas (TLs). BCLs are classified as follows: mucosa-associated lymphoid tissue (MALT) lymphomas, diffuse large BCLs (DLBCLs), follicular lymphomas (FLs), mantle cell lymphomas (MCLs), and Burkitt lymphomas (BLs). TLs can be further classified as enteropathyassociated TL (EATL), adult T-cell leukaemia/lymphoma (ATLL), and angioimmunoblastic TL (AITL). The Ann Arbor classification (8) is generally used to stage MLs $(10,11)$. GI MLs often deviate from the stages of the Ann Arbor classification because most major lesions are extranodal. Therefore, in this study, we used the Lugano classification $\left(\mathrm{I}_{1} \mathrm{II}_{2}, \mathrm{II}_{2}, \mathrm{II}_{\mathrm{E}}\right.$, and $\left.\mathrm{IV}\right)$ developed at the International Malignant Lymphoma Conference, instead of the Ann Arbor classification, for staging (12). The staging workup included blood cell count and serum chemistry; computed tomography scans of the neck, chest, abdomen, and pelvis (183 patients); magnetic resonance imaging of the abdomen (27 patients); gallium scintigraphy (66 patients); and bone marrow aspiration or biopsy (139 patients). Localization of lesions was assessed using EGD (all patients), TCS (87 patients), BAE (18 patients), and CE (24 patients). A total GI tract examination was performed in 29 cases (using EGD, BAE and/or CE, and TCS); EGD and BAE and/or CE examinations, 3 cases; EGD and TCS examinations, 58 cases; and EGD-only examination, 100 cases. We extracted cases that could be staged using these diagnostic imaging methods.

Data collection. Patients were classified into six groups based on the histological types of lymphoma (MALT lymphoma, DLBCL, FL, MCL, BL, and TL). We analysed the stages and locations of the lesions. The location of the lesions was evaluated by dividing the GI tract into nine parts (esophagus, stomach, duodenum, jejunum, ileum, terminal ileum, cecum, colon, and rectum). We defined cases showing lymphomatous involvement in a single segment of the GI tract as the single-lesion group and cases showing lymphomatous involvement in multiple segments as the overlap group. We extracted cases in which lesions were found in more than two segments (overlap cases). We then defined the proportion of cases with lymphomatous involvement in multiple segments of the GI tract as the overlap rate. For overlap cases, we analysed the overlap rate and the prevalence of GI segments including the small intestine (jejunum, ileum, and terminal ileum) for each histopathological type. We also assessed locations of lesions by a combination of tests (combination of EGD, BAE and/or CE, and TCS). Macroscopic diagnosis was also made. In the overlap group, the lesions were macroscopically classified as polypoid, ulcerative, polyposis [multiple lymphomatous polyposis (MLP)], diffusely infiltrating, or mixed type (13). We evaluated the distribution of the macroscopic types evaluated at 4 sites (stomach, duodenum, small intestine including the terminal ileum, and large intestine including the rectum). The stages were classified as early $\left(\mathrm{I}, \mathrm{II}_{1}\right)$ and advanced $\left(\mathrm{II}_{2}, \mathrm{II}_{\mathrm{E}}, \mathrm{IV}\right)$, and the degree of progression was assessed for each case. The stages of lesions of the various histological types were evaluated. Additionally, to assess the increase in the frequency of using $\mathrm{BAE}$ and $\mathrm{CE}$, which are important diagnostic tools for detecting small intestinal lesions, we divided the cases based on the period when the lesions were observed into the first half (October 2007 to April 2013, n=95) and the second half (May 2013 to January 2021, n=95).

Outcome measures. The primary outcome was the multi-site overlap rate in all cases and for every histopathological type. The secondary outcome was the prevalence of small intestinal lesions; the small intestine has not been investigated for a long time in overlap cases.

Statistical analyses. Ages were expressed as means, and proportions were expressed as percentages. Chi-squared tests were used for all statistical tests. All $p$-values were two-tailed, and $p<0.05$ was considered statistically significant. All statistical analyses were performed using the Statistical Package for the Social Sciences (SPSS), version 20.0 for Windows (IBM Corporation, Armonk, NY, USA).

Ethical considerations. This study was conducted in accordance with the provisions of the Declaration of Helsinki. Ethical approval for the study was given by the ethics review board of the Jikei University School of Medicine [approval number: 29-308(8924)], and all consent requirements were met based on the institutional policy for retrospective studies.

\section{Results}

The mean age of all 190 patients was 62.1 years (range=3288 years); 106 patients were male and 84 were female. Based on histological analyses, there were 99 cases of MALT lymphoma (52.1\%), 49 DLBCL cases $(25.8 \%), 29$ FL cases (15.3\%), 6 MCL cases (3.2\%), 3 BL cases (1.6\%), and 4 TL cases $(2.0 \%)$. With respect to staging, using the Lugano international classification, 117 cases $(61.6 \%)$ were in stage I, 21 cases $(11.1 \%)$ in stage $\mathrm{II}_{1}, 12$ cases $(6.3 \%)$ in stage $\mathrm{II}_{2}$, 4 cases $(2.1 \%)$ in stage $\mathrm{II}_{\mathrm{E}}$, and 36 cases $(18.9 \%)$ in stage IV (Table I). Most MALT lymphoma (95/99 96.0\%) cases were in the early stage. The most frequent location of lesions was the stomach, followed by the duodenum, small intestine (jejunum, ileum, and terminal ileum), and large intestine (colon and rectum). About $98 \%$ of patients with MALT lymphoma and $78 \%$ of patients with DLBCL had gastric lesions, whereas $76 \%$ of patients with FL had duodenal lesions. Twenty-five (13.2\%) patients had both gastric and/or duodenal and/or small intestinal and/or large intestinal involvement (overlap group). The distribution of histological types among overlap cases was as follows: MCL 100\% (6/6), FL $27.6 \%$ (8/29), DLBCL $16.3 \%$ (8/49), and MALT lymphoma $3.0 \%$ (3/99) (Table II). Patients with MCL, FL, and DLBCL had significantly higher overlap rates than those with MALT lymphomas $(p<0.001, p<0.001, p=0.006$, 
Table I. Patient characteristics $(n=190)$.

\begin{tabular}{lclc}
\hline Characteristics & N $(\%)$ & Characteristics & N $(\%)$ \\
\hline Age (years) & $32-88$ & Clinical stage (Lugano) & \\
$\quad$ Median & 62.1 & I & $117(61.6)$ \\
& & II1 & $21(11.1)$ \\
Gender & & II2 & $12(6.3)$ \\
Male & $106(56)$ & IIE & $4(2.1)$ \\
Female & $84(44)$ & IV & $36(18.9)$ \\
Histological type & & & \\
MALT & $99(52.1)$ & & $25(13.2)$ \\
DLBCL & $49(25.8)$ & Overlapping & $165(86.8)$ \\
FL & $29(15.3)$ & Non-overlapping & \\
MCL & $6(3.2)$ & & $25(13.2)$ \\
BL & $3(1.6)$ & & \\
TL ${ }^{\dagger}$ & $4(2.0)$ & Small intestinal lesion & \\
\hline
\end{tabular}

MALT: Mucosa-associated lymphoid tissue; DLBCL: diffuse large Bcell lymphoma; FL: follicular lymphoma; MCL: mantle cell lymphoma; BL: Burkitt's lymphoma; TL: T-cell lymphoma. †'Further classified as enteropathy-associated T-cell lymphoma (EATL), adult T-cell leukaemia lymphoma (ATLL), and angioimmunoblastic T-cell lymphoma (AITL).

respectively) (Figure 1). Small intestinal lesions were found in $25(13.2 \%)$ cases: $9(5.5 \%)$ cases in the single-lesion group and $16(64.0 \%)$ in the overlap group (Table III). The prevalence of small intestinal MLs was significantly higher in the overlap group than in the single-lesion group $(p<0.001)$ (Figure 2). As shown in the localization of all histological cases (Figure 3), all overlap MCL cases and most of the FL cases had small intestinal MLs. The cases involving overlapping lesions had more advanced stages than those with single lesions. Lesions in advanced stages were observed in $60 \%(15 / 25)$ and $22.4 \%(37 / 165)$ of cases with overlapping and single lesions, respectively; this difference was statistically significant $(p<0.001)$.

In summary, the overlap rate of ML lesions was significantly high in MCL, FL, and DLBCL cases. The most frequent location of overlapping lesions was the small intestine and the prevalence rate of advanced stage cases was high in the overlap group. In particular, the prevalence of small intestinal lesions was significantly high in MCL and FL cases.

Among the 29 cases that underwent examination of the whole GI tract, 10 had MALT lymphoma, 6 had DLBCL, 9 had FL, 3 had MCL, and 1 had BL. Twelve (41.4\%) patients had both gastric and/or duodenal and/or small intestinal and/or large intestinal involvement (overlap group). The distribution of histological types among overlap cases was as follows: MCL $100 \%$ (3/3), FL $66.7 \%$ (6/9), DLBCL $16.7 \%(1 / 6)$, and MALT lymphoma $20 \%$ (2/10). Small intestinal lesions were found in $18(62.1 \%)$ cases, including $7(41.2 \%)$ cases in the single-lesion group and 11 cases $(91.7 \%)$ in the overlap group. The location of lesions as
Table II. Overlapping rate according to the histological type.

\begin{tabular}{lcccc}
\hline $\begin{array}{l}\text { Histological } \\
\text { type }\end{array}$ & \multicolumn{2}{c}{ Number of segments } & $\begin{array}{c}\text { Overlap rate } \\
(\%)\end{array}$ & $\begin{array}{c}\text { Total } \\
(\mathrm{n})\end{array}$ \\
\cline { 2 - 3 } & $\begin{array}{c}\text { Single } \\
\text { segments }\end{array}$ & $\begin{array}{c}\text { Multiple } \\
\text { segments }\end{array}$ & & \\
\hline MALT & 96 & 3 & 3.0 & 99 \\
DLBCL & 41 & 8 & 16.3 & 49 \\
FL & 21 & 8 & 27.6 & 29 \\
MCL & 0 & 6 & 100 & 6 \\
BL & 3 & 0 & 0 & 3 \\
TL & 4 & 0 & 0 & 4 \\
Total & 165 & 25 & 13.2 & 190 \\
\hline
\end{tabular}

MALT: Mucosa-associated lymphoid tissue; DLBCL: diffuse large Bcell lymphoma; FL: follicular lymphoma; MCL: mantle cell lymphoma; BL: Burkitt's lymphoma; TL: T-cell lymphoma.

evaluated by a combination of tests revealed that in the 32 cases examined by BAE and/or CE, a total of 20 patients had small intestinal lesions. In 87 cases examined by TCS, a total of 10 people had lesions in the terminal ileum. Regarding the macroscopic diagnosis, the ulcerative type was found predominantly in the stomach, the MLP type was found in the duodenum and small intestine, and the MLP and polyposis types were found in the large intestine. BAE and/or CE were performed in 32 patients, and the frequency of using BAE and/or CE in evaluating patients was $8.4 \%$ (8/95) in the first half (October 2007 to April 2013) and $25.3 \%$ (24/95) in the second half (May 2013 to January 2021). Additionally, 2 cases in the first half and 16 cases in the second half underwent BAE or CE to screen for small intestinal lesions.

\section{Discussion}

Our cohort study revealed that many GI lymphoma cases had overlapping lesions in the GI tract. We found that the overlap rate was especially high in MCL, FL, and DLBCL cases. Additionally, among the overlapping cases, there were many overlapping small intestinal lesions. In our study, small intestinal lesions were examined via $\mathrm{BAE}$ or $\mathrm{CE}$ in 32 cases (16.8\% of the total patients). Of these, 18 patients underwent BAE, 24 patients underwent $\mathrm{CE}$, and 10 patients underwent both. Among the 32 patients who underwent BAE or CE, 14 were suspected of having small intestinal lesions ( 7 cases, a small intestinal mass observed via imaging; and 7 cases, obscure GI bleeding), and 18 patients were screened. The reason the rate of detection of small intestinal lesions increased in the latter half of the observation period of about 14 years is most likely due to the increased use of BAE/CE, which is a test for examining the small intestine. BAE and $\mathrm{CE}$ tests are increasingly being adopted (14, 15); this may 


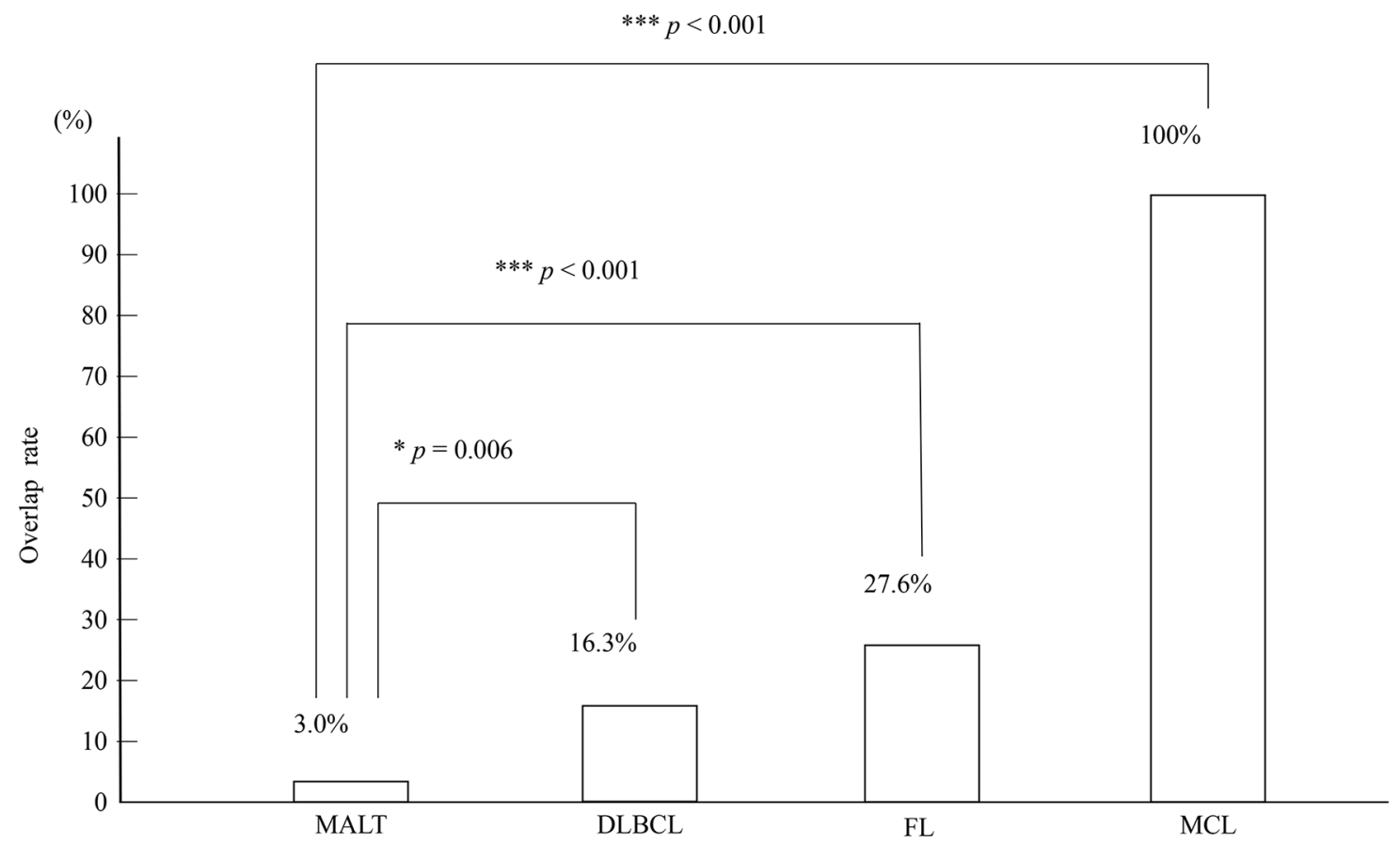

Figure 1. Overlapping rates of different lymphoma types. MALT: Mucosa-associated lymphoid tissue; DLBCL: diffuse large B-cell lymphoma; FL: follicular lymphoma; MCL: mantle cell lymphoma.

contribute to increased detection and diagnosis of small bowel lesions in cases of ML. Recently, CE and BAE have been performed in many cases for the staging of MLs, and our small intestine screening test detected small intestinal lesions in $38.9 \%(7 / 18)$ of cases. For FL, small bowel lesions were observed in $60 \%$ of cases $(3 / 5)$ during screening. In the future, if $\mathrm{CE}$ and/or BAE are used more frequently for screening small intestinal lesions, it may be possible to more accurately assess small intestinal MLs. For the detection of GI ML lesions, it is ideal to observe the small intestine in detail via $\mathrm{CE}$ and/or BAE, as they enable more accurate staging.

Several studies have focused on primary GI MLs and reported that $5-15 \%$ of cases involved overlapping GI tract lesions $(4,6,9,16,17)$. These reports are similar to the findings of our study. Conversely, few reports have analysed small intestinal lesions in ML patients in detail. Several reports have reported that FLs are most frequently found in the duodenum; however, other reports showed that such lesions could be found in the small intestine following the widespread use of BAE and CE $(14,15)$ Takata et al. conducted a multicentre, retrospective study to determine the anatomical distribution of GI FLs (18). They evaluated the tumour location in 125 patients and the entire GI tract was examined via DBE or CE in 70 patients. The second portion of the duodenum (81\%) was the most frequently involved GIFL site, followed by the jejunum (40\%) and ileum (22\%). Of the 70 patients who underwent examination of the entire GI tract, $54(77 \%)$ had tumors in the second portion of the duodenum. Small intestinal lesions were also found in $85 \%$ of these patients. These findings are similar to those of previous small-scale studies $(14,15)$. Thus, small intestinal lesions, including those in the duodenum, are more common in FL cases. Our study also indicates that small intestinal lesions (mainly terminal ileum lesions) are more common in MCL cases. Several studies have reported the features of GI MLs (such as incidence rate, subtype frequency, localization, and prognosis) (19-22). They revealed that the prognoses of ML cases involving overlapping lesions and advanced stages were significantly poorer than those of ML cases involving single lesions and early stages $(9,14,23)$. In this study, we did not evaluate patients' prognoses; however, we hypothesized that prognosis would be poorer in cases with overlapping lesions because they are at more advanced stages.

$\mathrm{CE}$ and small intestinal endoscopy may be useful for detecting and evaluating small intestinal lesions in ML. It is ideal to analyse cases with overlapping lesions further and inspect the small intestinal lesions using $\mathrm{CE}$ and/or BAE, if possible. Furthermore, a deeper insertion of EGD (up to the $3^{\text {rd }}$ portion) and TCS (up to the terminal ileum) may be helpful. In cases of MCL and FL, it is especially important to examine the small intestine because of the high overlapping rate of small intestinal ML lesions. We believe 
Table III. Presence of small intestinal lesions.

\begin{tabular}{|c|c|c|c|c|c|}
\hline \multicolumn{3}{|c|}{ Single cases } & \multicolumn{3}{|c|}{ Overlap cases } \\
\hline & $\begin{array}{c}\text { Rate } \\
\text { of small } \\
\text { intestinal } \\
\text { lesions }(\%)\end{array}$ & Total & & $\begin{array}{c}\text { Rate } \\
\text { of small } \\
\text { intestinal } \\
\text { lesions (\%) }\end{array}$ & Total \\
\hline MALT & $0(0)$ & 96 & MALT & $1(33.3)$ & 3 \\
\hline DLBCL & $5(12.2)$ & 41 & DLBCL & $2(25.0)$ & 8 \\
\hline FL & $2(9.5)$ & 21 & FL & $7(87.5)$ & 8 \\
\hline MCL & $0(0)$ & 0 & MCL & $6(100)$ & 6 \\
\hline BL & $1(33.3)$ & 3 & $\mathrm{BL}$ & $0(0)$ & 0 \\
\hline TL & $1(25)$ & 4 & $\mathrm{TL}$ & $0(0)$ & 0 \\
\hline Total & $9(5.5)$ & 165 & Total & $16(64)$ & 25 \\
\hline
\end{tabular}

MALT: Mucosa-associated lymphoid tissue; DLBCL: diffuse large Bcell lymphoma; FL: follicular lymphoma; MCL: mantle cell lymphoma; BL: Burkitt's lymphoma; TL: T-cell lymphoma.

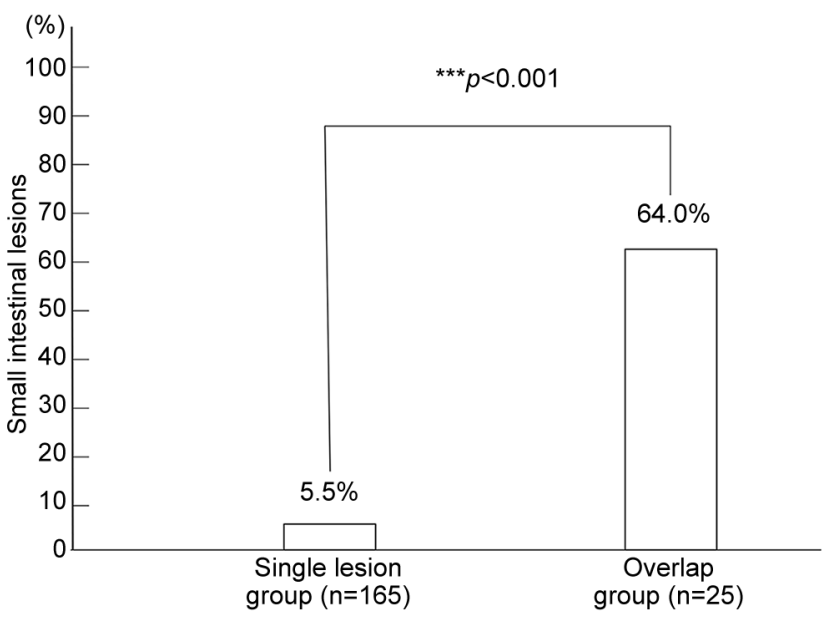

Figure 2. Percentage of small intestinal lesions in single- and multiplelesion cases.

\section{A MALT ( 3 cases )}

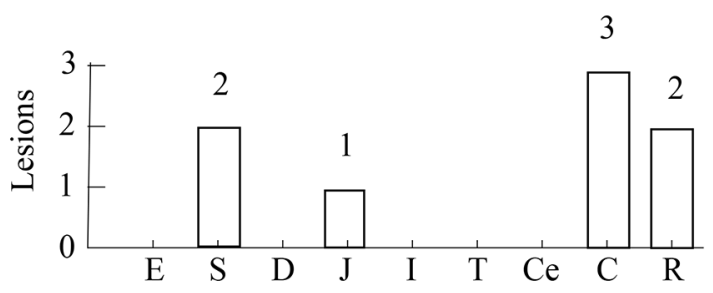

C MCL ( 6 cases )

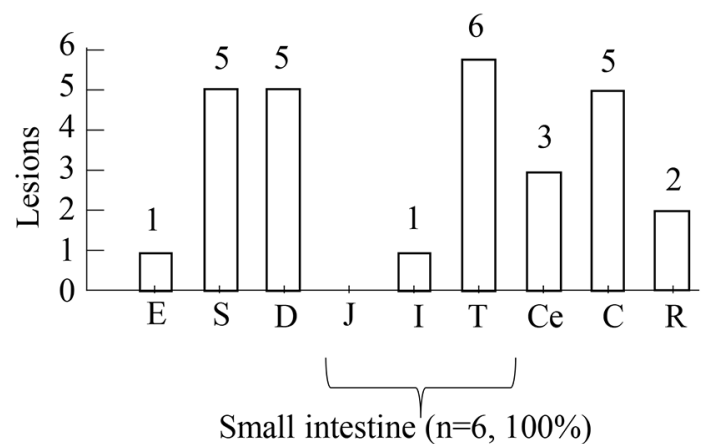

B DLBCL ( 8 cases )

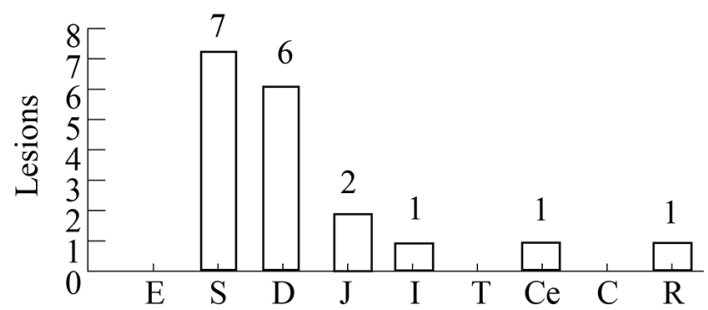

D FL ( 8 cases $)$

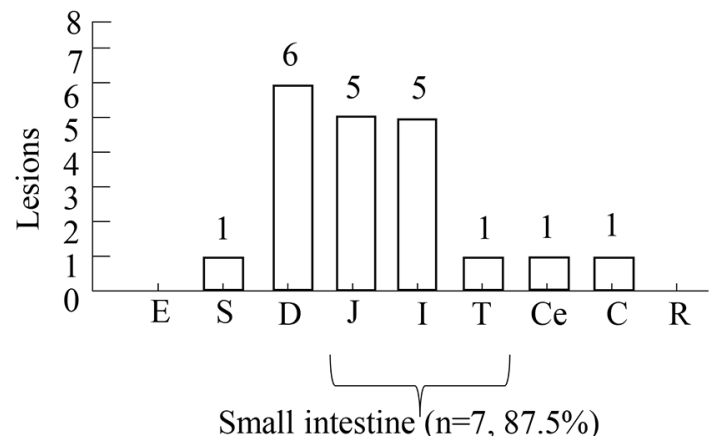

Figure 3. Localization of all histological cases (overlapping cases). MALT: Mucosa-associated lymphoid tissue; DLBCL: diffuse large B-cell lymphoma; FL: follicular lymphoma; MCL: mantle cell lymphoma; E: esophagus; S: stomach; D: duodenum; J: jejunum; I: ileum; T: terminal ileum; Ce: cecum; C: colon; $R$ : rectum.

that assessing the presence or absence of ML lesions in the entire GI tract is very important and recommended for accurate disease staging and making an appropriate decision on treatment strategy.
Our study had some limitations, mainly related to its retrospective nature and single-centre design. Further prospective studies comprising a larger number of patients are needed to clarify the importance of 
evaluating the GI tract, including the small intestine, in patients with MLs.

\section{Conflicts of Interest}

The Authors report no conflicts of interest in relation to this study.

\section{Authors' Contributions}

YM and TY designed the study and wrote the manuscript. YM, TY, and $\mathrm{AH}$ analysed and interpreted the data. YM, HM, YA, YN, RM, MN, RS, TS, TK, and KS collected and assembled the data. TY and MS were study supervisors. All Authors read and approved the final manuscript.

\section{Acknowledgements}

The Authors would like to thank Editage (www.editage.com) for English language editing assistance.

\section{References}

1 Amer MH and el-Akkad S: Gastrointestinal lymphoma in adults: clinical features and management of 300 cases. Gastroenterology 106(4): 846-858, 1994. PMID: 8143991. DOI: 10.1016/00165085(94)90742-0

2 Yoshino T, Miyake K, Ichimura K, Mannami T, Ohara N, Hamazaki $\mathrm{S}$ and Akagi T: Increased incidence of follicular lymphoma in the duodenum. Am J Surg Pathol 24(5): 688-693, 2000. PMID: 10800987. DOI: 10.1097/00000478-20000500000007

3 Psyrri A, Papageorgiou S and Economopoulos T: Primary extranodal lymphomas of stomach: clinical presentation, diagnostic pitfalls and management. Ann Oncol 19(12): 19921999, 2008. PMID: 18647965. DOI: 10.1093/annonc/mdn525

4 Nakamura S, Matsumoto T, Iida M, Yao T and Tsuneyoshi M: Primary gastrointestinal lymphoma in Japan: a clinicopathologic analysis of 455 patients with special reference to its time trends. Cancer 97(10): 2462-2473, 2003. PMID: 12733145. DOI: $10.1002 /$ cncr. 11415

5 Swerdlow SH, Campo E, Harris NL, Jaffe ES, Pileri SA, Stein $\mathrm{H}$ and Thiele $\mathrm{J}$ : WHO classification of tumours of Haematopoietic and Lymphoid Tissues, Volume 2, $4^{\text {th }}$ edition. Lyon, France, IARC, 2008.

6 Nakamura S and Matsumoto T: Gastrointestinal lymphoma: recent advances in diagnosis and treatment. Digestion 87(3): 182-188, 2013. PMID: 23635497. DOI: $10.1159 / 000350051$

7 Lewin KJ, Ranchod M and Dorfman RF: Lymphomas of the gastrointestinal tract: a study of 117 cases presenting with gastrointestinal disease. Cancer 42(2): 693-707, 1978. PMID: 354774. DOI: 10.1002/1097-0142(197808)42:2<693::aidcncr2820420241>3.0.co;2-j

8 Carbone PP, Kaplan HS, Musshoff K, Smithers DW and Tubiana M: Report of the committee on Hodgkin's disease staging classification. Cancer Res 31(11): 1860-1861, 1971. PMID: 5121694.

9 Koch P, del Valle F, Berdel WE, Willich NA, Reers B, Hiddemann W, Grothaus-Pinke B, Reinartz G, Brockmann J, Temmesfeld A, Schmitz R, Rübe C, Probst A, Jaenke G, Bodenstein H, Junker A, Pott C, Schultze J, Heinecke A,
Parwaresch R, Tiemann M and German Multicenter Study Group: Primary gastrointestinal non-Hodgkin's lymphoma: I. Anatomic and histologic distribution, clinical features, and survival data of 371 patients registered in the German Multicenter Study GIT NHL 01/92. J Clin Oncol 19(18): 3861-3873, 2001. PMID: 11559724. DOI: $10.1200 / J C O .2001 .19 .18 .3861$

10 Moormeier JA, Williams SF and Golomb HM: The staging of non-Hodgkin's lymphomas. Semin Oncol 17(1): 43-50, 1990. PMID: 2406917.

11 Rosenberg SA: Validity of the Ann Arbor staging classification for the non-Hodgkin's lymphomas. Cancer Treat Rep 61(6): 1023-1027, 1977. PMID: 902260.

12 Rohatiner A, d'Amore F, Coiffier B, Crowther D, Gospodarowicz M, Isaacson P, Lister TA, Norton A, Salem P and Shipp M: Report on a workshop convened to discuss the pathological and staging classifications of gastrointestinal tract lymphoma. Ann Oncol 5(5): 397-400, 1994. PMID: 8075046. DOI: 10.1093/oxfordjournals.annonc.a058869

13 Nakamura S, Matsumoto T, Takeshita M, Kurahara K, Yao T, Tsuneyoshi M, Iida M and Fujishima M: A clinicopathologic study of primary small intestine lymphoma: prognostic significance of mucosa-associated lymphoid tissue-derived lymphoma. Cancer 88(2): 286-294, 2000. PMID: 10640959. DOI: $10.1002 /($ sici) 1097-0142(20000115)88:2<286::aid-cncr7> 3.0.co;2-z

14 Nakamura S, Matsumoto T, Umeno J, Yanai S, Shono Y, Suekane H, Hirahashi M, Yao T and Iida M: Endoscopic features of intestinal follicular lymphoma: the value of double-balloon enteroscopy. Endoscopy 39 Suppl 1: E26-E27, 2007. PMID: 17285496. DOI: $10.1055 / \mathrm{s}-2007-966223$

15 Kodama M, Kitadai Y, Shishido T, Shimamoto M, Fukumoto A, Masuda H, Tanaka S, Yoshihara M, Sakai A, Nakayama H and Chayama K: Primary follicular lymphoma of the gastrointestinal tract: a retrospective case series. Endoscopy 40(4): 343-346, 2008. PMID: 18067068. DOI: 10.1055/s-2007-995365

16 Radaszkiewicz T, Dragosics B and Bauer P: Gastrointestinal malignant lymphomas of the mucosa-associated lymphoid tissue: factors relevant to prognosis. Gastroenterology 102(5): 1628-1638, 1992. PMID: 1568573. DOI: 10.1016/0016-5085(92)91723-h

17 d'Amore F, Brincker H, Grønbaek K, Thorling K, Pedersen M, Jensen MK, Andersen E, Pedersen NT and Mortensen LS: NonHodgkin's lymphoma of the gastrointestinal tract: a populationbased analysis of incidence, geographic distribution, clinicopathologic presentation features, and prognosis. Danish Lymphoma Study Group. J Clin Oncol 12(8): 1673-1684, 1994. PMID: 8040680. DOI: 10.1200/JCO.1994.12.8.1673

18 Takata K, Okada H, Ohmiya N, Nakamura S, Kitadai Y, Tari A, Akamatsu T, Kawai H, Tanaka S, Araki H, Yoshida T, Okumura H, Nishisaki H, Sagawa T, Watanabe N, Arima N, Takatsu N, Nakamura M, Yanai S, Kaya H, Morito T, Sato Y, Moriwaki H, Sakamoto C, Niwa Y, Goto H, Chiba T, Matsumoto T, Ennishi D, Kinoshita $\mathrm{T}$ and Yoshino T: Primary gastrointestinal follicular lymphoma involving the duodenal second portion is a distinct entity: a multicenter, retrospective analysis in Japan. Cancer Sci 102(8): 1532-1536, 2011. PMID: 21561531. DOI: 10.1111/j. 1349-7006.2011.01980.x

19 Chen Y, Chen Y, Chen S, Wu L, Xu L, Lian G, Yang K, Li Y, Zeng L and Huang K: Primary gastrointestinal lymphoma: A retrospective multicenter clinical study of 415 cases in Chinese province of Guangdong and a systematic review containing 5075 
Chinese patients. Medicine (Baltimore) 94(47): e2119, 2015. PMID: 26632732. DOI: 10.1097/MD .0000000000002119

20 Fujishima F, Katsushima H, Fukuhara N, Konosu-Fukaya S, Nakamura Y, Sasano H and Ichinohasama R: Incidence rate, subtype frequency, and occurrence site of malignant lymphoma in the gastrointestinal tract: Population-based analysis in Miyagi, Japan. Tohoku J Exp Med 245(3): 159-165, 2018. PMID: 29998914. DOI: 10.1620/tjem.245.159

21 Shi Z, Ding H, Shen QW, Lu XG, Chen JY, Chen X and Tang $\mathrm{X}$ : The clinical manifestation, survival outcome and predictive prognostic factors of 137 patients with primary gastrointestinal lymphoma (PGIL): Strobe compliant. Medicine (Baltimore) 97(1): e9583, 2018. PMID: 29505542. DOI: 10.1097/MD 0000000000009583

22 Wang W, Lin P, Yao H, Jia X and Sun J: Clinical analysis of primary gastrointestinal non-Hodgkin's lymphoma. Pak J Med Sci 33(6): 1406-1411, 2017. PMID: 29492068. DOI: 10.12669/ pjms.336.13631
23 Ruskoné-Fourmestraux A, Aegerter P, Delmer A, Brousse N, Galian A and Rambaud JC: Primary digestive tract lymphoma: a prospective multicentric study of 91 patients. Groupe d'Etude des Lymphomes Digestifs. Gastroenterology 105(6): 1662-1671, 1993. PMID: 8253342. DOI: 10.1016/0016-5085(93)91061-1

Received June 14, 2021

Revised July 8, 2021

Accepted July 9, 2021 